\title{
Regulation of the TCA cycle and the general amino acid permease by overflow metabolism in Rhizobium leguminosarum
}

School of Animal and Microbial Sciences, University of Reading, Whiteknights PO Box 228, Reading RG6 6AJ, UK

\author{
David L. Walshaw, Adam Wilkinson, Mathius Mundy, Mary Smith \\ and Philip S. Poole
}

Author for correspondence: Philip S. Poole. Tel: +44 1189318895 . Fax : +441189316671. e-mail : p.s.poole@ reading.ac.uk

Mutants of Rhizobium leguminosarum were selected that were altered in the uptake activity of the general amino acid permease (Aap). The main class of mutant maps to suCA and SUCD, which are part of a gene cluster moh-sucCDAB, which codes for malate dehydrogenase ( $m d h$ ), succinyl-CoA synthetase (suCCD) and components of the 2-oxoglutarate dehydrogenase complex (suCAB). Mutation of either suCC or SUCD prevents expression of 2-oxoglutarate dehydrogenase (suCAB). Conversely, mutation of suCA or sucB results in much higher levels of succinyl-CoA synthetase and malate dehydrogenase activity. These results suggest that the genes moh-sucCDAB may constitute an operon. suc mutants, unlike the wild-type, excrete large quantities of glutamate and 2 oxoglutarate. Concomitant with mutation of SUCA or SUCD, the intracellular concentration of glutamate but not 2-oxoglutarate was highly elevated, suggesting that 2-oxoglutarate normally feeds into the glutamate pool. Elevation of the intracellular glutamate pool appeared to be coupled to glutamate excretion as part of an overflow pathway for regulation of the TCA cycle. Amino acid uptake via the Aap of $R$. leguminosarum was strongly inhibited in the suc mutants, even though the transcription level of the aap operon was the same as the wild-type. This is consistent with previous observations that the Aap, which influences glutamate excretion in $R$. leguminosarum, has uptake inhibited when excretion occurs. Another class of mutant impaired in uptake by the Aap is mutated in polyhydroxybutyrate synthase (phaC). Mutants of succinyl-CoA synthetase (suCD) or 2-oxoglutarate dehydrogenase (suCA) form ineffective nodules. However, mutants of aap, which are unable to grow on glutamate as a carbon source in laboratory culture, show wild-type levels of nitrogen fixation. This indicates that glutamate is not an important carbon and energy source in the bacteroid. Instead glutamate synthesis, like polyhydroxybutyrate synthesis, appears to be a sink for carbon and reductant, formed when the 2-oxoglutarate dehydrogenase complex is blocked. This is in accord with previous observations that bacteroids synthesize high concentrations of glutamate. Overall the data show that the TCA cycle in R. leguminosarum is regulated by amino acid excretion and polyhydroxybutyrate biosynthesis which act as overflow pathways for excess carbon and reductant.

Keywords: 2-oxoglutarate dehydrogenase, malate dehydrogenase, succinyl-CoA synthetase, poly- $\beta$-hydroxybutyrate 


\section{INTRODUCTION}

The legume-Rhizobium symbiosis requires the exchange of carbon and nitrogen between the plant and bacterial symbionts to fuel nitrogen fixation. In return for a source of fixed nitrogen as ammonia the plant must provide the bacterial partner (bacteroid) with a carbon and energy source. A substantial body of evidence indicates that the principal carbon source is a $\mathrm{C}_{4}$ dicarboxylic acid, either L-malate, fumarate or succinate. This conclusion is based on the observation that $\mathrm{C}_{4}$-dicarboxylates support high rates of respiration in isolated bacteroids (Glenn \& Dilworth, 1981) and mutations in either malic enzyme or the structural gene for the dicarboxylate transport system $(d c t A)$ abolish nitrogen fixation, while mutations preventing sugar catabolism have no effect (Ronson \& Primrose, 1979; Ronson et al., 1981; Finan et al., 1983; Glenn et al., 1984; Arwas et al., 1985; Bolton et al., 1986; Engelke et al., 1987). Furthermore, gluconeogenic enzymes are expressed in bacteroids of Rhizobium leguminosarum, Sinorhizobium meliloti and Rhizobium strain NGR234, indicating that significant quantities of sugars are not supplied to bacteroids by the plant (McKay et al., 1985; Finan et al., 1991; Osteras et al., 1991). Consistent with these observations, the plant-derived peribacteroid membrane of Bradyrhizobium japonicum, which is relatively impermeable to sugars, has an active uptake system for dicarboxylic acids (Day \& Udvardi, 1993). However, nutrient exchange may be more complex, since isolated bacteroids of $R$. leguminosarum and $B$. japonicum are known to excrete amino acids, particularly alanine and to a lesser extent aspartate (Appels \& Haaker, 1991; Kouchi et al., 1991; Rosendahl et al., 1992). While on the one hand this has led to the proposal that a form of malate-aspartate shuttle may operate between the plant and bacteroid, the alternative explanation is that amino acids may be excreted to remove excess carbon and reducing equivalents (McDermott et al., 1989; Appels \& Haaker, 1991).

Labelling studies with isolated bacteroids of $B$. japonicum have shown that intracellular glutamate accumulates rapidly after addition of precursors such as malate (Salminen \& Streeter, 1987). Similarly, when whole nodules of peas and soybeans were incubated in ${ }^{14} \mathrm{CO}_{2}$, bacteroids of both species accumulated large pools of glutamate and alanine (Salminen \& Streeter, 1992). These studies suggest that the TCA cycle may become partially blocked at the 2-oxoglutarate dehydrogenase complex, leading to glutamate biosynthesis. It has also been shown that the 2oxoglutarate dehydrogenase complex is very sensitive to inhibition by a high $\mathrm{NADH} / \mathrm{NAD}^{+}$ratio (Salminen $\&$ Streeter, 1990). If such a redox inhibition of the 2oxoglutarate dehydrogenase complex occurs in the low $\mathrm{O}_{2}$ environment of the nodule then glutamate biosynthesis may occur. Amino acid biosynthesis and excretion may thus be part of an overflow pathway that removes excess carbon and reductant when the TCA cycle becomes limited or blocked. In addition, polyhydroxybutyrate (PHB) biosynthesis may function in a similar way in rhizobia (Bergersen \& Turner, 1990; Povolo et al., 1994; Cevallos et al., 1996).

Given the importance of amino acid metabolism in the nodule we have been investigating amino acid transport and metabolism in R. leguminosarum. Studies revealed that $R$. leguminosarum has a novel general amino acid permease (Aap) able to transport a wide range of amino acids with high affinity (Poole et al., 1985; Walshaw \& Poole, 1996). We have recently cloned this system and shown it to be an ABC transporter composed of four genes (aapJQMP) that code for a complex able to promote the active uptake of a broad range of L-amino acids (Walshaw \& Poole, 1996). This is unusual in that previously characterized $\mathrm{ABC}$ transporters of amino acids are highly specific for a single amino acid or a group of structurally similar amino acids. A further novel feature of the Aap is that it influences the efflux of intracellularly synthesized glutamate. For example, mutation of aapJ prevented $76 \%$ of glutamate excretion under appropriate conditions. We have proposed that either the Aap is bi-directional, allowing efflux of solute itself, or that it regulates a separate efflux channel/transporter (Walshaw \& Poole, 1996).

Glutamate excretion by laboratory cultures of $R$. leguminosarum bv. viciae strain 3841 can be induced when they are grown on glucose/aspartate; this effect is dependent on the active unregulated accumulation of aspartate by the Dct system (Reid et al., 1996). Aspartate loaded by the Dct system presumably acts as an amino group donor to 2-oxoglutarate forming glutamate, which is then excreted. Under these conditions uptake by the Aap is severely reduced even though transcription of the operon is slightly elevated (Reid et al., 1996). These results suggest that the uptake activity of the Aap may be regulated by the TCA cycle via the synthesis of amino acids. In this study we demonstrate that such regulation does occur. A key enzyme is shown to be the 2-oxoglutarate dehydrogenase complex, confirming it as a pivotal step in the regulation of the TCA cycle in $R$. leguminosarum.

\section{METHODS}

Bacterial strains and culture conditions. Bacterial strains, bacteriophages and plasmids used in this study are described in Table 1 . R. leguminosarum strains were grown at $28^{\circ} \mathrm{C}$ on either TY (Beringer, 1974) or acid minimal salts (AMS) medium (pH 7·2) (Poole et al., 1994b). All carbon and nitrogen sources were at $10 \mathrm{mM}$ unless otherwise stated. Antibiotics were used at the following concentrations in $\mu \mathrm{g} \mathrm{ml}^{-1}$ : kanamycin 40, streptomycin 500, tetracycline 2 (in AMS) and 5 (in TY), and gentamicin 20. Escherichia coli strains were grown at $37^{\circ} \mathrm{C}$ on $\mathrm{LB}$, with antibiotic concentrations in $\mu \mathrm{g} \mathrm{ml}^{-1}$ as follows: kanamycin 25 , tetracycline 10 , gentamicin 5 and ampicillin 50 .

DNA and genetic manipulations. All routine DNA analysis was done essentially as described by Sambrook et al. (1989). Conjugations were done as previously described (Poole et al., 1994b). Transductions were done with the bacteriophage RL38 as described by Buchanan-Wollaston (1979). Strain 3841 was mutagenized with $\operatorname{Tn} 5$ by conjugation with $E$. coli $\mathrm{S} 17-1$ 
Table 1. Bacterial strains, plasmids and bacteriophages used

\begin{tabular}{|c|c|c|}
\hline $\begin{array}{l}\text { Strain, phage or } \\
\text { plasmid }\end{array}$ & Description & Source or reference \\
\hline \multicolumn{3}{|l|}{ Bacteria } \\
\hline \multicolumn{3}{|l|}{ R. leguminosarum } \\
\hline 3841 & $\operatorname{Str}^{\mathrm{R}}$ derivative of strain 300 & $\begin{array}{l}\text { Johnston \& Beringer (1975); } \\
\text { Glenn et al. }(1980)\end{array}$ \\
\hline RU116 & Strain $3841 s u c D:: \operatorname{Tn} 5$ & This work \\
\hline RU137 & Strain 3841 phaC: : Tn5 & This work \\
\hline RU156 & Strain 3841 sucA: : $\operatorname{Tn} 5$ & This work \\
\hline RU724 & pRU3067 homogenote in strain 3841, sucA: : Tn5 & This work \\
\hline RU725 & pRU3059 homogenote in strain 3841 , sucC: $: \operatorname{Tn} 5$ & This work \\
\hline RU726 & pRU3069 homogenote in strain 3841, sucB: $: \operatorname{Tn} 5$ & This work \\
\hline RU733 & pRU3061 homogenote in strain 3841 , sucA: : Tn5 & This work \\
\hline \multicolumn{3}{|l|}{ E. coli } \\
\hline 803 & met gal & Wood (1966) \\
\hline S17-1 & $\begin{array}{l}\text { pro } h s d R \text { recA }[\mathrm{RP} 4-2(\mathrm{Tc}:: \mathrm{Mu})(\mathrm{Km}:: \mathrm{Tn} 7)], \mathrm{RP} 4 \text { integrated into its } \\
\text { chromosome }\end{array}$ & Simon et al. (1983) \\
\hline MC1061 & bsdR mcrB araD139 $\Delta($ araABC-leu $) 7679 \Delta$ lacX74 galU galK rpsL thi & Meissner et al. (1987) \\
\hline \multicolumn{3}{|l|}{ Plasmids } \\
\hline pAR36A & R. leguminosarum glnII:lacZ translational fusion in $\mathrm{pMP} 220$ & Patriarca et al. (1992) \\
\hline pBluescript II SK - & $\begin{array}{l}\text { Phagemid, pUC19 derivative, } \mathrm{f} 1 \text { origin of replication, ColE1 } \\
\text { replicon, Amp }{ }^{\mathrm{R}}\end{array}$ & Stratagene \\
\hline pJQ200 & pACYC derivative, P15A origin of replication, $\mathrm{Gm}^{\mathrm{R}}$ & Quandt \& Hynes (1993) \\
\hline pMP220 & IncP transcriptional fusion vector, $\mathrm{Tc}^{\mathrm{R}}$ & Spaink et al. (1987) \\
\hline pPHJI1 & P-group chaser plasmid, $\mathrm{Gm}^{\mathrm{R}}$ & Hirsch \& Beringer (1984) \\
\hline pRU3004 & pLAFR 1 cosmid containing $m d h$-sucCDAB from strain 3841 & This work \\
\hline pRU3024 & pLAFR 1 cosmid containing aapJQMP from strain 3841 & Walshaw \& Poole (1996) \\
\hline pRU3028 & pRU3024 aapJ: :Tn5-lacZ & Walshaw \& Poole (1996) \\
\hline pRU3059 & pRU3004 sucC: : Tn5-lacZ & This work \\
\hline pRU3061 & pRU3004 sucA: : Tn5-lacZ & This work \\
\hline pRU3067 & pRU3004 sucA: :Tn5-lacZ & This work \\
\hline pRU3068 & pRU3004 sucA: : Tn5-lacZ & This work \\
\hline pRU3069 & pRU3004 sucB: : Tn5-lacZ & This work \\
\hline pRU3070 & pRU3004 mdb: : Tn5-lacZ & This work \\
\hline pRU3075 & pRU3004 sucA: : Tn5-lacZ & This work \\
\hline pRU3076 & pRU3004 $m d b:: \operatorname{Tn} 5-l a c Z$ & This work \\
\hline pSP72 & Promoterless cloning vector, $A m p^{R}$ & Promega \\
\hline pSUP202-1: : Tn5 & $m o b \mathrm{Km}^{\mathrm{R}}$ & Simon et al. (1983) \\
\hline \multicolumn{3}{|l|}{ Bacteriophages } \\
\hline$\lambda:: \operatorname{Tn} 5-\operatorname{lac} Z$ & $\lambda$ carrying the $\operatorname{Tn} 5-\mathrm{B} 20$ transposon & Simon et al. (1989) \\
\hline RL38 & Generalized transducing phage of $R$. leguminosarum & Buchanan-Wollaston (1979) \\
\hline
\end{tabular}

containing pSUP202-1: : Tn5 essentially as described by Simon et al. (1983). Cosmid pRU3024 was mutagenized with Tn5-lac $Z$ by using $\lambda$ containing the transposon derivative $\mathrm{B} 20$ essentially as described by Simon et al. (1989). To create chromosomal mutations, mutated cosmids were conjugated into $R$. leguminosarum strain 3841. After purification, the incompatible plasmid pPHJI1 was conjugated into each strain and the homogenotes isolated by the technique of Ruvkun $\&$ Ausubel (1981).

All sequencing was done by the cycle-sequencing method using a Promega fmol kit according to the manufacturer's instructions. GCG software was used for computer-assisted sequence analysis. Primers $P_{0}$ and $P_{15}$ have the sequences GTTCAGGACGCTACTTG and GGATCCATAATTTTTTCCTCC, respectively.
Transport assays. $R$. leguminosarum strains were prepared and transport assays done as previously described (Poole $e t$ al., 1985 ), using in each case a total solute concentration of $25 \mu \mathrm{M}$. The specific activities of labelled solutes in the assays were: $\mathrm{L}$ [U- ${ }^{14} \mathrm{C}$ ]aspartic acid (354 $\mathrm{MBq} \mathrm{mmol}^{-1}$ ), L- $\left[\mathrm{U}-{ }^{14} \mathrm{C}\right]$ glutamic acid (357 MBq mmol ${ }^{-1}$ ), L-[U- ${ }^{14} \mathrm{C}$ ]alanine $\left(348 \mathrm{MBq} \mathrm{mmol}^{-1}\right)$, 2-amino $\left[1-{ }^{14} \mathrm{C}\right]$ isobutyrate $\left(2 \cdot 22 \mathrm{GBq} \mathrm{mmol}^{-1}\right), \quad\left[2,3-{ }^{14} \mathrm{C}\right]-$ succinic acid $\left(4 \mathrm{GBq} \mathrm{mmol}^{-1}\right)$ and $\mathrm{D}-\left[\mathrm{U}-{ }^{14} \mathrm{C}\right]$ glucose $(358 \mathrm{MBq}$ $\mathrm{mmol}^{-1}$ ).

Enzyme assays. Cultures of $R$. leguminosarum strains $(500 \mathrm{ml})$ were harvested at a cell density of approximately $5 \times 10^{8}$ cells $\mathrm{ml}^{-1}$, washed and resuspended in $10 \mathrm{ml} 40 \mathrm{mM}$ HEPES pH $7 \cdot 0$, containing $1 \mathrm{mM}$ DTT. Cells were disrupted by two passages through a French press at $69 \mathrm{MPa}$. Following 
centrifugation at $30000 \mathrm{~g}$ for $20 \mathrm{~min}$, the supernatant was used for enzyme assay. Citrate synthase (EC 4.1.3.7), 2oxoglutarate dehydrogenase (EC 1.2.4.2), isocitrate dehydrogenase (EC 1.1.1.41) and succinyl-CoA synthetase (EC 6.2.1.5) were assayed according to Reeves et al. (1971). Malate dehydrogenase (EC 1.1.1.37) was assayed by the technique of Saroso et al. (1986). $\beta$-Galactosidase fusions were assayed according to Miller (1972), with modifications as described by Poole et al. (1994a).

Excretion assays. Cells of strains 3841, RU116 and RU156 were grown to mid-exponential phase overnight on malate $/ \mathrm{NH}_{4} \mathrm{Cl}$, glucose $/ \mathrm{NH}_{4} \mathrm{Cl}$ /aspartate or glucose $/ \mathrm{NH}_{4} \mathrm{Cl}$ minimal medium, harvested aseptically, washed once in AMS and resuspended to an $\mathrm{OD}_{600}$ of 1 in AMS. The same carbon and nitrogen sources were then added to each culture at $10 \mathrm{mM}$ except for aspartate, which was $20 \mathrm{mM}$. Resuspended cells were incubated at $28^{\circ} \mathrm{C}$ and samples removed at 0,60 , 150 and $270 \mathrm{~min}$. Samples were centrifuged at $11000 \mathrm{~g}$ for $15 \mathrm{~min}$ to remove cells and the supernatant assayed for glutamate by the technique of Bernt \& Bergmeyer (1974). Aspartate was measured by a procedure adapted from Bergmeyer et al. (1974). Each assay contained $150 \mu \mathrm{mol}$ potassium phosphate (pH 7.2), $0.3 \mu \mathrm{mol} \mathrm{NADH}, 15 \mu \mathrm{mol}$ 2-oxoglutarate, $2 \mathrm{U}$ aspartate aminotransferase, $2 \mathrm{U}$ malate dehydrogenase and $250 \mu \mathrm{l}$ of sample, in a total volume of $1.5 \mathrm{ml}$. Alanine was determined in a final volume of $1.5 \mathrm{ml}$ containing $75 \mu \mathrm{mol}$ glycine, $60 \mu \mathrm{mol}$ hydrazine monohydrate, $4 \mu \mathrm{mol} \mathrm{NAD}{ }^{+}, 0.5 \mathrm{U}$ alanine dehydrogenase and $250 \mu \mathrm{l}$ of sample. Assays for aspartate and alanine were incubated and read as for the glutamate determination.

2-Oxoglutarate assays contained $150 \mu \mathrm{mol}$ potassium phosphate (pH 7.2), $0.3 \mu \mathrm{mol} \mathrm{NADH}, 75 \mu \mathrm{mol}$ aspartate, $2 \mathrm{U}$ aspartate aminotransferase, $2 \mathrm{U}$ malate dehydrogenase and $250 \mu \mathrm{l}$ of sample, in a total volume of $1.5 \mathrm{ml}$. Assays were incubated and read as for the glutamate determination. Oxaloacetate was measured as for 2-oxoglutarate except that aspartate and aspartate aminotransferase were omitted.

Intracellular metabolite concentrations. Cultures of $R$. leguminosarum strains $(500 \mathrm{ml})$ were grown on glucose $/ \mathrm{NH}_{4} \mathrm{Cl}$, harvested by centrifugation at a cell density of approximately $5 \times 10^{8}$ cells $\mathrm{ml}^{-1}$, washed three times in AMS and resuspended in $15 \mathrm{ml} 100 \mathrm{mM}$ HEPES, $\mathrm{pH} 7 \cdot 2$, all operations being carried out at $5{ }^{\circ} \mathrm{C}$. Cells were disrupted by two passages through a French press at $69000 \mathrm{kPa}$, centrifuged at $30000 \mathrm{~g}, 5^{\circ} \mathrm{C}$, for $20 \mathrm{~min}$, and the supernatant assayed for protein content. Ice-cold $10 \%$ trichloroacetic acid $(2.5 \mathrm{ml})$ was added to $5 \mathrm{ml}$ of supernatant. After centrifugation at $3500 \mathrm{~g}, 5^{\circ} \mathrm{C}$, for $15 \mathrm{~min}$, the $\mathrm{pH}$ of the supernatant was adjusted to 7.0 and the volume made up to $8 \mathrm{ml}$. Samples of the neutralized supernatant were assayed for glutamate and 2oxoglutarate as described above.

PHB determination. $\mathrm{PHB}$ content was determined in cultures $(50 \mathrm{ml})$ grown on glucose $/ \mathrm{NH}_{4} \mathrm{Cl}$ to a cell density of approximately $10^{9}$ cells $\mathrm{ml}^{-1}$, washed in AMS, pelleted by centrifugation and resuspended in technical grade sodium hypochlorite $(5 \mathrm{ml})$. Tenfold and 100-fold dilutions of this were then made in sodium hypochlorite and incubated at $37^{\circ} \mathrm{C}$ for $1 \mathrm{~h}$. The PHB content was then determined by the technique of Law \& Slepecky (1961).

Protein determination. The protein concentration of whole cells was determined by the method of Lowry, using BSA as standard.

\section{RESULTS}

\section{Aspartate resistant mutants of $R$. leguminosarum strain 3841}

We were interested in selecting mutants of $R$. leguminosarum altered in the regulation of transport via the Aap. Since uptake via the Aap is severely reduced in the presence of aspartate in the growth medium (Reid et al., 1996) we considered that it might be possible to isolate regulatory mutants by selecting cells that had become resistant to high levels of aspartate. Toxicity is apparently caused by the loading of aspartate via the Dct system, with $d c t$ mutants being resistant to high levels of aspartate $(150 \mathrm{mM})$ in the growth medium (Reid et al., 1996; Walshaw \& Poole, 1996). Conversely, aap mutants are more severely affected by the presence of aspartate in the growth medium, consistent with a role for the Aap in excretion of glutamate formed from aspartate (Walshaw \& Poole, 1996).

Over $100000 \mathrm{Tn} 5$ mutants of strain 3841 were plated on AMS agar containing glucose $/ \mathrm{NH}_{4} \mathrm{Cl}$ as the carbon/nitrogen source, $100 \mathrm{mM}$ aspartate and kanamycin at $80 \mu \mathrm{g} \mathrm{ml}^{-1}$. Fifty colonies, from among several hundred able to grow on this medium, were purified and the uptake of aspartate and glucose by the resulting strains was investigated. Approximately half of the mutants analysed had severely impaired rates of aspartate uptake, even when grown in the absence of aspartate in the growth medium (data not shown). Whenever there was a reduction in aspartate transport there was a concomitant, though not so severe, reduction in glucose transport, a different phenotype from that resulting from a mutation of the Aap (Walshaw \& Poole, 1996) suggesting that these mutants were altered in a gene (or genes) with a more global impact. Two strains from this class, RU116 and RU156, were chosen for further study. A second class of mutant, represented by strain RU137, had a reduction of approximately $60 \%$ in aspartate transport.

\section{Amino acid transport in strains RU116 and RU115}

Two acidic and two aliphatic amino acids were chosen to test uptake by the Aap. The Aap is responsible for approximately $80 \%$ of glutamate and aspartate transport and approximately $55 \%$ of uptake of the two aliphatic amino acids. The uptake of all the amino acids tested was significantly reduced in strains RU116 and RU156 relative to strain 3841 (Table 2). In glucosegrown cells of RU156 for example, aspartate transport was less than $5 \%$ of that in the wild-type strain. While glucose transport in strain RU156 was affected, it was still $30 \%$ of that in strain 3841. 2-Aminoisobutyrate (AIB) transport was also measured because this amino acid is transported by the Aap but is not metabolized in $R$. leguminosarum strain 3841. Since the rate of AIB transport was lowered in strains RU116 and RU156, it appears that this reduction is not simply the result of a reduced rate of metabolic incorporation. When strains RU116 and RU156 were grown on succinate, the 
Table 2. Rates of amino acid transport in $R$. leguminosarum strains RU116 and RU156 grown on glucose/ $\mathrm{NH}_{4} \mathrm{Cl}$ and succinate $/ \mathrm{NH}_{4} \mathrm{Cl}$

Rates of uptake are expressed as nmol $\mathrm{min}^{-1}(\mathrm{mg} \text { protein })^{-1}$. Values are the mean \pm SEM of determinations from three or more independent cultures. AIB, 2-aminoisobutyrate. ND, Not determined.

\begin{tabular}{|lcccccc|}
\hline \multirow{2}{*}{ Growth conditions and strain } & \multicolumn{5}{c|}{ Rate of uptake with substrate shown: } \\
\cline { 2 - 6 } & L-Aspartate & L-Glutamate & L-Alanine & AIB & D-Glucose & Succinate \\
\hline Glucose/ $\mathrm{NH}_{4} \mathrm{Cl}$ & & & & & & \\
3841 & $3 \cdot 9 \pm 0 \cdot 1$ & $5 \cdot 6 \pm 0 \cdot 4$ & $6 \cdot 4 \pm 0 \cdot 7$ & $4 \cdot 3 \pm 0 \cdot 6$ & $39 \cdot 5 \pm 3 \cdot 2$ & ND \\
RU116 & $0 \cdot 6 \pm 0 \cdot 1$ & $0 \cdot 8 \pm 0 \cdot 3$ & $2 \cdot 0 \pm 0 \cdot 2$ & $1 \cdot 2 \pm 0 \cdot 1$ & $19 \cdot 5 \pm 0 \cdot 6$ & ND \\
RU156 & $0 \cdot 2 \pm 0 \cdot 1$ & $0 \cdot 3 \pm 0 \cdot 1$ & $1 \cdot 2 \pm 0 \cdot 1$ & $0 \cdot 1 \pm 0 \cdot 0$ & $12 \cdot 4 \pm 1 \cdot 1$ & ND \\
Succinate/ $\mathrm{NH}_{4} \mathrm{Cl}$ & $3 \cdot 1 \pm 0 \cdot 1$ & $3 \cdot 6 \pm 0 \cdot 4$ & ND & ND & ND & $46 \cdot 7 \pm 0 \cdot 2$ \\
3841 & $1 \cdot 3 \pm 0 \cdot 1$ & $1 \cdot 4 \pm 0 \cdot 4$ & ND & ND & ND & $31 \cdot 2 \pm 0 \cdot 6$ \\
RU116 & $0 \cdot 6 \pm 0 \cdot 1$ & $0 \cdot 5 \pm 0 \cdot 1$ & ND & ND & ND & $22 \cdot 7 \pm 3 \cdot 9$ \\
RU156 & & & & & & \\
\hline
\end{tabular}

reduction in the rates of glutamate and aspartate transport, relative to the wild-type, were less than those found in glucose-grown cultures. However, the reduction in amino acid uptake was still significantly greater than that of succinate uptake in each case. Succinate uptake in strains RU116 and RU156 grown on succinate was also less severely affected than glucose uptake in the same strains grown on glucose. This suggests that growth on succinate is able to partially rescue amino acid uptake in strains RU116 and RU156 as a result of a global effect within the cell.

Strains 3841, RU116 and RU156 had mean generation times on glucose of 270,405 and $721 \mathrm{~min}$, respectively. However, on succinate the respective mean generation times were 220,315 and $305 \mathrm{~min}$, indicating that the mutations in strains RU116 and RU156 were more deleterious to glucose catabolism than they were to that of succinate. Strain RU137 grew at a similar rate to strain 3841 .

\section{Genetic analysis of mutant strains}

In order to confirm that the insertion of $\mathrm{Tn} 5$ was linked to the phenotype of the chosen aspartate toxic-escape mutants, the kanamycin resistance marker of each of strains RU116, RU137 and RU156 was transduced to strain 3841. Five transductants from each mutant strain were purified and each found to be resistant to $100 \mathrm{mM}$ aspartate. In addition, aspartate and glucose uptake in the transductants was similar to the rates in their respective transductional donor strains (data not shown). These results show that the phenotypes of strains RU116, RU137 and RU156 are each tightly linked to a single $\operatorname{Tn} 5$ insertion.

Chromosomal DNA from strain RU116, RU137 and RU156 was isolated, restricted with EcoRI and the resulting restriction fragments randomly cloned into the EcoRI site of pBluescript II SK-. In each case, the resulting DNA was used to transform $E$. coli strain MC1061, and $\mathrm{Km}^{\mathrm{R}} \mathrm{Amp} \mathrm{p}^{\mathrm{R}}$ transformants were selected. BamHI and HindIII sub-clones were made for each transposon-containing clone to enable the left and right arms to be separated for sequencing.

Each of the sub-clones was then partially sequenced using primer $\mathrm{P}_{0}$, which binds to the end of IS50, yielding sequence directly in the flanking chromosomal DNA. The GenBank and EMBL databases were searched for sequences showing homology to each of the six possible translations of each sequence. One translation of the nucleotide sequence from chromosomal DNA flanking the transposon in strain RU116 had $54 \%$ identity to residues 223-289 of sucD from E. coli, which codes for the $\alpha$-subunit of succinyl-CoA synthetase. One translation of the nucleotide sequence from the transposon in strain RU156 had $68 \%$ identity to sucA from E. coli, which codes for the 2-oxoglutarate dehydrogenase subunit of the 2-oxoglutarate dehydrogenase complex. These data show that strains RU116 and RU156 are mutated in genes coding for successive enzymes of the TCA cycle.

One translation of the nucleotide sequence from strain RU137 showed $61 \%$ and $81 \%$ identity over 88 amino acids to poly- $\beta$-hydroxybutyrate synthase (encoded by phaC) from $S$. meliloti and $R$. phaseoli, respectively (Povolo et al., 1994; Cevallos et al., 1996). This suggests that biosynthesis of PHB is blocked in strain RU137. To confirm this, the PHB content was measured in strains 3841 and RU137 grown on glucose/ammonia; it was $61 \mu \mathrm{g}(\mathrm{mg} \mathrm{dry} \mathrm{wt})^{-1}$ and $4 \cdot 1 \mu \mathrm{g}(\mathrm{mg} \text { dry wt })^{-1}$, respectively.

If strains RU116 and RU156 are mutated in succinylCoA synthetase and 2-oxoglutarate dehydrogenase, respectively, they should not grow on arabinose or glutamate as the carbon source. This is because the catabolic pathway in $R$. leguminosarum for these substrates enters the TCA cycle at 2-oxoglutarate 
Table 3. TCA cycle enzyme activities in glucose/ $\mathrm{NH}_{4} \mathrm{Cl}$-grown aspartate toxic-escape Tn5 mutants of $R$. leguminosarum strain 3841

Activities are expressed as $\mathrm{nmol} \mathrm{min}^{-1}(\mathrm{mg} \text { protein })^{-1}$. Values are the mean $\pm \mathrm{SEM}$ of three or more independent determinations, except the succinyl-CoA synthetase values, which are the mean of two independent determinations. 2-ODH, 2-oxoglutarate dehydrogenase; SCS, succinyl-CoA synthetase; $\mathrm{MDH}$, malate dehydrogenase; ICDH, isocitrate dehydrogenase; CS, citrate synthase. uD, Undetectable; ND, not determined.

\begin{tabular}{|lcccccccc|}
\hline \multirow{2}{*}{ Enzyme } & \multicolumn{9}{c}{ Activity of strain: } & & \\
\cline { 2 - 8 } & 3841 & RU116 & RU137 & RU156 & RU724 & RU725 & RU726 & RU733 \\
\hline 2-ODH & $109 \pm 10$ & $6 \pm 2$ & $42 \pm 12$ & UD & UD & UD & UD & UD \\
SCS & 55 & 20 & ND & 252 & ND & 22 & 98 & ND \\
MDH & $4978 \pm 833$ & $18830 \pm 2524$ & $3893 \pm 1835$ & $17435 \pm 1622$ & ND & ND & ND & ND \\
ICDH & $864 \pm 164$ & $904 \pm 94$ & $890 \pm 61$ & $957 \pm 66$ & ND & ND & ND & ND \\
CS & $166 \pm 26$ & $227 \pm 31$ & $100 \pm 23$ & $123 \pm 37$ & ND & ND & ND & ND \\
\hline
\end{tabular}

(Dilworth et al., 1986). As expected, strains RU116 and RU156 were unable to grow on arabinose or glutamate as the sole carbon source.

\section{TCA cycle enzyme activities in mutant strains of $R$. leguminosarum}

Activities of the corresponding TCA cycle enzymes were assayed in strains 3841, RU116, RU156 and RU137 (Table 3). The complete loss of 2-oxoglutarate dehydrogenase activity was expected in RU156, since this strain is mutated in the gene encoding for the 2oxoglutarate dehydrogenase sub-unit of the 2oxoglutarate dehydrogenase complex. The observation that strain RU116 exhibited negligible 2-oxoglutarate dehydrogenase activity suggests that the transposon in RU116 (sucD) may be polar on sucA. It is relevant to note that in $E$. coli these genes are clustered as part of the sucABCD operon (Darlison et al., 1984; Spencer et al., 1984; Buck et al., 1985). The ability of a sucD mutant to be polar on sucA suggests that they are also clustered in $R$. leguminosarum although the gene order is likely to be different from that in $E$. coli, because the direction of transcription in E. coli is from sucA towards sucD (Buck et al., 1985). We show below that this is the case.

The mutation in sucD (strain RU116), which codes for the $\alpha$-subunit of succinyl-CoA synthetase, reduced succinyl-CoA synthetase activity by $64 \%$ (Table 3 ). While this is consistent with the sequence data for the location of the transposon in strain RU116 it does suggest the possibility of a second gene product with succinyl-CoA synthetase activity. This activity was not due to endogenous organic acids in the enzyme extract as omitting succinate from the enzyme assay resulted in only $3 \%$ of the activity when succinate was added.

Interestingly, succinyl-CoA synthetase levels in strain RU156 were greatly increased in comparison to strain 3841 , suggesting that mutation of $s u c A$, and hence loss of 2-oxoglutarate dehydrogenase activity, elevates either the specific activity or expression of succinyl-CoA synthetase. In addition the activity of malate dehydrogenase was also greatly increased in both RU116 and RU156. Activities of citrate synthase and isocitrate dehydrogenase were not increased in strain RU156 relative to 3841 , so the effect does not occur for all TCA cycle enzymes.

The activity of 2-oxoglutarate dehydrogenase was reduced in strain RU137 to $38 \%$ of the activity measured in strain 3841 (Table 3). Malate dehydrogenase and isocitrate dehydrogenase were unaffected. This suggests that PHB biosynthesis is involved in the regulation of certain TCA cycle enzymes.

\section{Structure of the mdh-suc operon}

A chromosomal library of strain 3841 (as EcoRI fragments in pLAFR1) was conjugated from E. coli strain 803 into strain RU156. Cosmid pRU3004 was isolated that restored the ability of strains RU156 and RU116 to grow on glutamate as the sole carbon source. Amino acid uptake via the Aap was also restored in the complemented strains to the wild-type level (data not shown).

Southern blotting of EcoRI digested chromosomal DNA from each of strains 3841, RU116, RU137 and RU156 with pRU3004 demonstrated that pRU3004 contained DNA homologous to the Tn5-containing EcoRI fragment in both RU116 and RU156, but not to that in RU137. In other bacteria, sucA and $s u c D$ are clustered with genes encoding other TCA cycle enzymes (Miles \& Guest, 1987; Nicholls et al., 1990; Nishiyama et al., 1991; Guest, 1992; Guest \& Russell, 1992). It was therefore anticipated that several $R$. leguminosarum TCA cycle genes might be carried by pRU3004, in addition to $s u c A$ and $s u c D$. Consequently, pRU3004 was subjected to further study, in an attempt to establish whether the effect on amino acid transport in strain 3841 was specific to the mutation of 2-oxoglutarate dehydrogenase and succinyl-CoA synthetase, or whether the TCA cycle in general was implicated. 


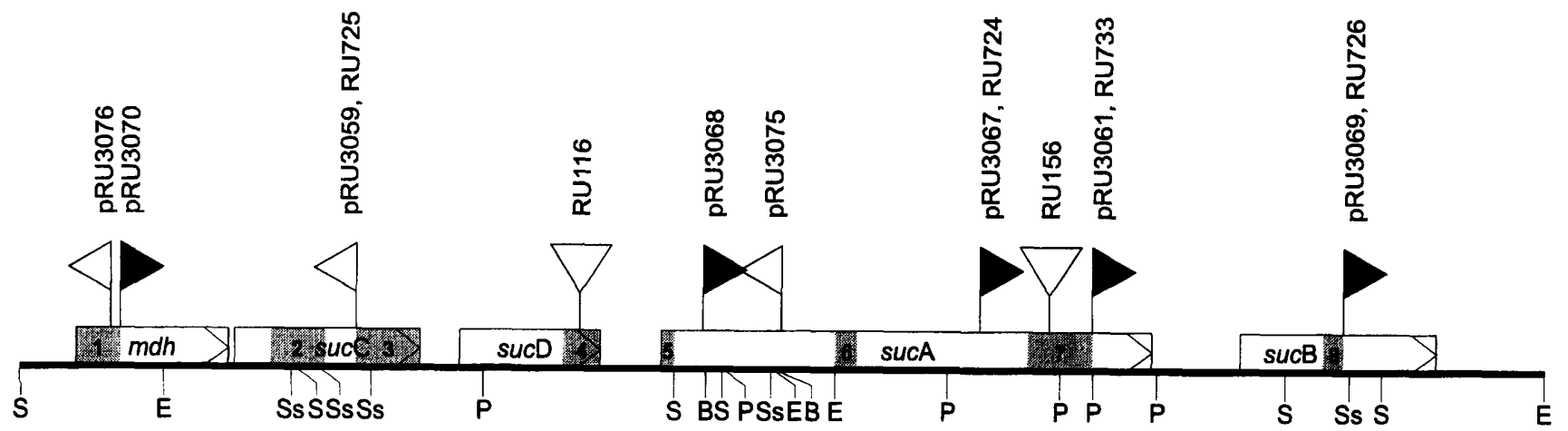

Fig. 1. Map of pRU3004 which contains the $m d h$-sucCDAB region from $R$. leguminosarum strain 3841 . Gene locations (numbered shaded areas) and orientations are based on identities to other bacterial genes as follows: $1,40.4 \%$ and $38 \%$ to $m d h$ in Photobacterium and E. coli, respectively; $2,45 \%$ to suCC in E. coli; $3,55 \%$ to suCC in $E$. coli; $4,54 \%$ to suCD in E. coli; $5,57 \%$ to suCA in Coxiella burnetti; $6,63 \%$ and $58 \%$ to suCA in C. burnetti and $E$. coli, respectively; $7,68 \%$ to suCA in $E$. coli; $8,50 \%$ to suCB in $E$. coli. The sizes of these genes are only approximate and are based on homology to other bacteria. Tn5-lacZ insertions are shown as flags with active fusions filled. Cosmid derivatives of pRU3004 carrying a transposon are indicated above the flag, as are the strain numbers where the transposon is integrated into the chromosome. Tn5 insertions are shown as $\nabla$. Restriction sites are B, BamHI; E, EcoRI; P, Pstl; S, Sall; Ss, Sstl.

Cosmid pRU3004 was restriction mapped and subjected to saturation mutagenesis with Tn5-lacZ (Fig. 1). The Tn5-lacZ-containing SalI fragments from pRU3059, pRU3061, pRU3069 and pRU3070 were each cloned into the Sall site of either pJQ200 or pSP72. Partial sequencing of the insert DNA in these plasmids was carried out using a primer $\left(\mathrm{P}_{15}\right)$ to the $5^{\prime}$ end of Tn5-lacZ, and either reverse, SK and KS primers to the pJQ200 polylinker, or the T7 primer to the pSP72 polylinker. One potential translation of each of these sequences exhibited significant identity to one of the TCA cycle enzymes 2-oxoglutarate dehydrogenase, succinyl-CoA synthetase or malate dehydrogenase from other organisms (Fig. 1). The locations of these identities within the various genes are consistent with the arrangements of Rhizobium genes proposed in Fig. 1.

To confirm the proposed directions of transcription for $m d h$ and sucCDAB, $\beta$-galactosidase activities, produced in a strain 3841 background by corresponding pRU3004 mutants, were investigated. Those cosmids in which lac $Z$ in the transposon was aligned with the proposed direction of transcription for the corresponding gene showed significantly higher activity than those in which lac $\mathrm{Z}$ was in the opposite orientation (data not shown) (Fig. 1).

In order to investigate directly the nature of the genes carried by pRU3004, activities of the corresponding TCA cycle enzymes were assayed in chromosomal mutants of these genes. Tn5-lacZ mutants of strain 3841 were generated by recombining the cosmids pRU3059, pRU3061, pRU3067 and pRU3069 into the chromosome to generate strains RU725, RU733, RU724 and RU726, respectively. Selection for the formation of homogenotes was carried out on both TY and AMS agar with succinate as the carbon source. No homogenotes of cosmids pRU3070 or pRU3076 could be isolated, possibly because mutation of $m d h$ is lethal. The enzyme activities were as expected for sucCDAB mutants (Table 3).

The polarity of sucCD mutations on $s u c A B$, as measured by 2-oxoglutarate dehydrogenase activity, is explicable by the gene order $m d h-s u c C D A B$ if they share a common promoter. In turn the increase in succinyl-CoA synthetase and malate dehydrogenase activity in sucAB mutations may be caused by their presence in a single operon.

\section{Transcription of the aap operon in SUCDA mutants of strain 3841}

Considering that amino acid uptake is particularly sensitive to disruption of the TCA cycle we wanted to determine how this effect is mediated. To determine whether regulation occurs at the transcriptional level, the activity of an aapJ: :lac $Z$ transcriptional fusion in strain 3841, RU116 and RU156 backgrounds was investigated.

Cosmid pRU3028, which has an active Tn5-lacZ fusion in aapJ, was conjugated into strains 3841 , RU116 and RU156. $\beta$-Galactosidase activity was then measured after growth on a good nitrogen source (ammonia) and a poor nitrogen source (glutamate) (Table 4). The activities in strain RU116 and RU156 backgrounds were generally very similar to those in strain 3841 , although activity in strain RU156 grown on glucose/glutamate was somewhat reduced, perhaps because this strain 
Table 4. $\beta$-Galactosidase activities in R. leguminosarum strains RU116 and RU156 containing aapJ or g/nll fusions

Strains were grown on AMS containing either glucose $/ \mathrm{NH}_{4} \mathrm{Cl}$ or glucose/glutamate at $10 \mathrm{mM}$. Activities are expressed as nmol min ${ }^{-1}$

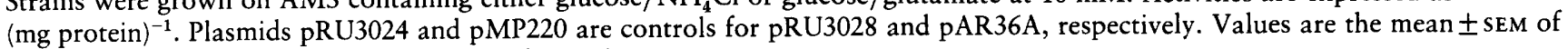
determinations from three or more independent cultures.

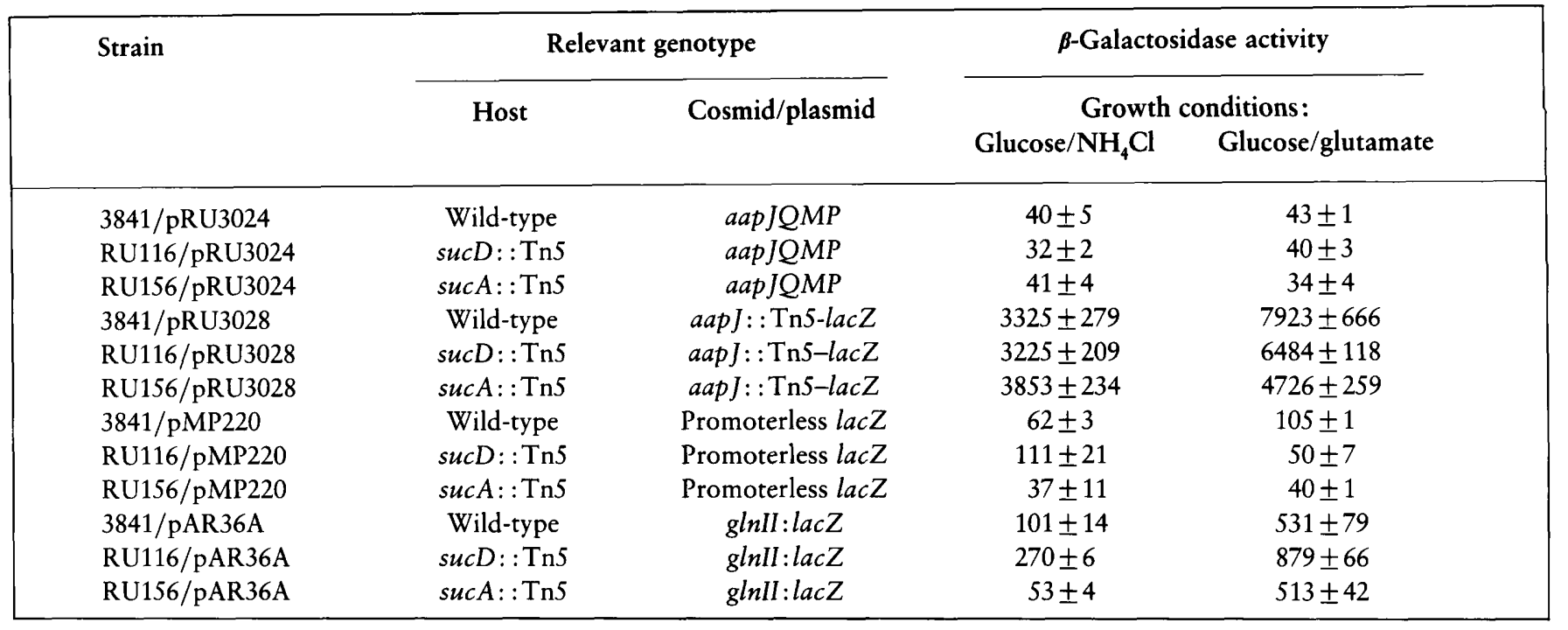

grew poorly under these conditions. Certainly, the activities of the fusions in strains RU116 and RU156 do not indicate a decrease in the transcription of the aap operon sufficient to account for the severe reduction in amino acid transport observed in strains RU116 and RU156 grown on glucose $/ \mathrm{NH}_{4} \mathrm{Cl}$ (Table 2).

It is interesting that, like the wild-type strain, both mutants exhibited repression of the aap operon when grown on $\mathrm{NH}_{4} \mathrm{Cl}$ as the nitrogen source. This implies that normal nitrogen regulation occurs in these strains. To test this further, $\beta$-galactosidase activities in strains RU116 and RU156 carrying the $R$. leguminosarum glnII : : lacZ reporter fusion pAR36A (Patriarca et al., 1992) were measured (Table 4). The glnIl gene is well documented as being regulated by the $n t r$ system in $R$. leguminosarum (Patriarca et al., 1992). Strains RU116, RU156 and 3841 had increased $\beta$-galactosidase activity in response to a change from nitrogen-rich to nitrogenpoor conditions. Since nitrogen regulation occurs normally in the TCA cycle mutants the very low amino acid transport rate in these strains is unlikely to be due to a regulatory effect of the $n t r$ system. Overall these data indicate that the very low rate of amino acid transport measured in strains RU116 and RU156 is a posttranscriptional effect.

\section{Intracellular concentrations and excretion of 2- oxoglutarate and glutamate}

Many of the effects on amino acid transport caused by disruption of the TCA cycle may result from changes in the intracellular concentration of metabolic intermediates. In particular, 2-oxoglutarate and glutamate concentrations may be affected by disruption of 2oxoglutarate dehydrogenase activity. The intracellular concentrations of these two compounds were therefore measured in cells grown on glucose/ammonia minimal medium. Whereas 2-oxoglutarate was undetectable in all strains, the glutamate concentrations in strains 3841 , RU116 and RU156 were 4, 12 and $52 \mathrm{mM}$, respectively. Thus, disruption of succinyl-CoA synthetase activity or 2-oxoglutarate dehydrogenase activity leads to a large increase in the intracellular glutamate pool.

Since the concentration of glutamate, but surprisingly not 2-oxoglutarate, increased dramatically in strains RU116 and RU156, we tested for the possible excretion into the growth medium of these and other metabolites. Supernatants from cultures growing on L-malate $/ \mathrm{NH}_{4} \mathrm{Cl}$ were assayed over time for alanine, aspartate, glutamate, 2-oxoglutarate and oxaloacetate (Fig. 2). L-Malate was provided as the carbon source because this is the most abundant $\mathrm{C}_{4}$-dicarboxylate in the nodule (Streeter, 1987), and consequently the most likely carbon source for the bacteroid. Although no excretion of alanine, aspartate or oxaloacetate was apparent, significant concentrations of glutamate and 2-oxoglutarate were detected in the supernatants from cultures of both strains RU116 and RU156. This is in contrast to the wild-type, for which no excretion of any of the four metabolites assayed was detected.

The excretion of certain metabolites, including 2oxoglutarate, by bacteria under particular metabolic conditions is well documented (Tempest \& Neijssel, 1992; Kramer, 1994; Encarnacion et al., 1995), and the excretion of 2-oxoglutarate by R. leguminosarum strains containing mutations that block the major catabolic pathway for this substrate is not surprising. However, the excretion of glutamate by strains RU116 and RU156 suggests that a proportion of the excess 2-oxoglutarate 
is converted to glutamate. The intracellular concentration data suggest that excess 2-oxoglutarate does not accumulate significantly in the mutants.

Since aspartate is a potential amino-donor in the production of glutamate from 2-oxoglutarate, we thought it possible that the escape of strains RU116 and RU156 from aspartate toxicity might be due to transamination of 2-oxoglutarate by aspartate, with subsequent excretion of the glutamate. To investigate this possibility, excretion of glutamate by strains 3841 , RU116 and RU156 grown on both glucose/ $\mathrm{NH}_{4} \mathrm{Cl}$ and glucose $/ \mathrm{NH}_{4} \mathrm{Cl} /$ aspartate was measured (Fig. 3). It should be noted that these experiments could not be done with L-malate as a carbon source since it blocks access of aspartate to the Dct carrier (Reid et al., 1996).

Excretion of glutamate by strains RU116 and RU156 was substantially increased by the presence of aspartate in the medium, consistent with increased transamination of 2-oxoglutarate, although 2-oxoglutarate excretion was still detectable (data not shown). This suggests that these strains are able to survive high levels of aspartate because the increased synthesis of intracellular 2oxoglutarate enables aspartate to be removed by transamination.

The presence of aspartate in the medium resulted in excretion of glutamate, but not 2-oxoglutarate, by strain 3841 (data not shown). It seems likely that the excreted glutamate was derived from increased transamination of 2-oxoglutarate by aspartate. These data suggest that increased glutamate synthesis prevents a build up in the concentration of 2-oxoglutarate. The observation that 2-oxoglutarate was not excreted by 3841 grown on glucose $/ \mathrm{NH}_{4} \mathrm{Cl} /$ aspartate implies that the rate of glutamate synthesis equals the rate of 2-oxoglutarate production. In strains RU116 and RU156 grown on glucose $/ \mathrm{NH}_{4} \mathrm{Cl}$ or malate $/ \mathrm{NH}_{4} \mathrm{Cl}$, the rate of 2oxoglutarate generation presumably exceeds the maximum rate of transamination to glutamate, and consequently 2-oxoglutarate is excreted.

Since strains RU116 and RU156 both have a high concentration of intracellular glutamate and excrete it at high rates it seemed possible that this substantial internal pool might lead to the apparent inhibition of amino acid uptake. Strains RU116 and RU156 were therefore incubated in minimal salts without carbon and nitrogen sources for up to $5 \mathrm{~h}$ to deplete the internal glutamate pool. No recovery in the transport rate occurred, nor was there any detectable glutamate excreted (data not shown). Since the data indicate that a large intracellular glutamate pool leads to excretion, this implies that a high intracellular glutamate concentration is not maintained in the absence of carbon and nitrogen sources over such an extended time period. The low rate of uptake by the Aap in strains RU116 amd RU156 is therefore unlikely to simply be the result of inhibition of uptake by the high intracellular glutamate pool. This suggests that under conditions where there is a sustained increase in the intracellular glutamate pool there may be a mechanism for modification of the Aap that prevents

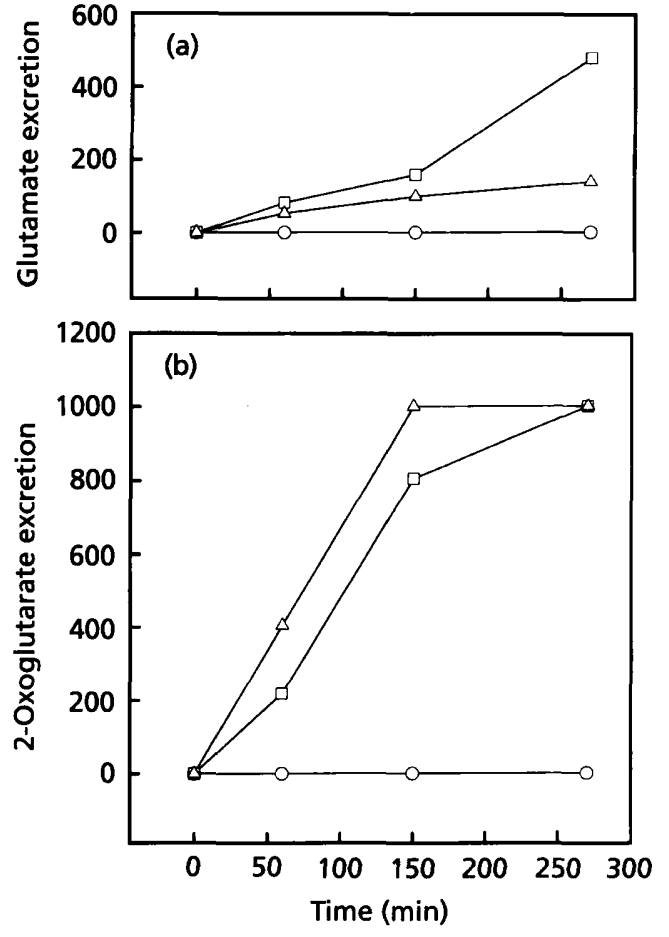

Fig. 2. Excretion of glutamate (a) and 2-oxoglutarate (b) by strains of $R$. leguminosarum grown on malate/ammonia minimal medium. $3841(0)$; RU156 $(\triangle)$; RU116 ( $\square)$. Data are given as $\mathrm{nmol}$ ( $\mathrm{mg}$ cell dry $\mathrm{wt}^{-1}{ }^{-1}$, from a single representative experiment.

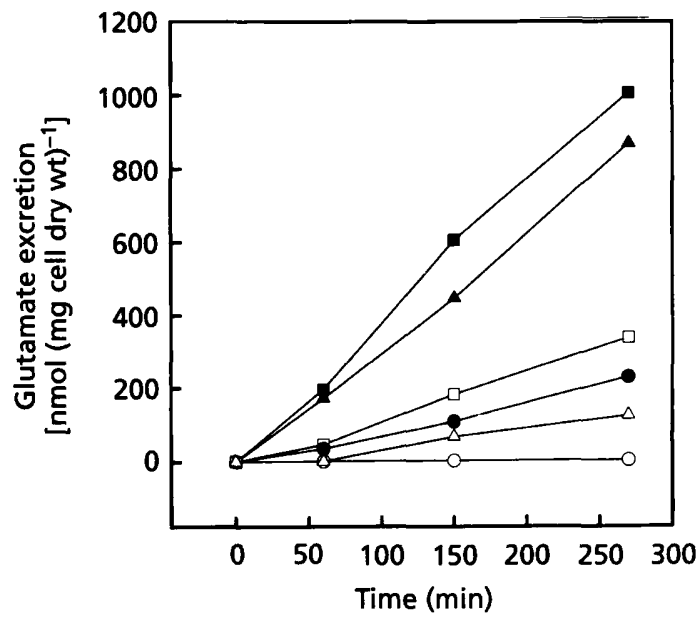

Fig. 3. Excretion of glutamate by strains of $R$. leguminosarum grown on glucose with either ammonia or aspartate minimal medium. $0,0,3841 ; \triangle, \Delta, R U 156 ; \square, \square, R U 116$. Open symbols, cells grown on glucose/ammonia/aspartate; filled symbols, cells grown on glucose/aspartate. Data are from a single representative experiment.

influx while allowing efflux. Uptake rates of solutes such as glucose, succinate and glutamate are very stable over a $5 \mathrm{~h}$ incubation in cells of strain 3841 resuspended in minimal salts. Thus, the failure of glutamate uptake to 
recover, after incubation to deplete the internal glutamate pool, is not likely to be due to a general loss of membrane uptake in starved cells.

\section{Plant properties}

Although both strain RU116 and strain RU156 nodulated peas, the nodules were extremely small, green and clearly ineffective. Kanamycin resistant bacteria could not be recovered from nodules produced by these strains. These results are consistent with an earlier report that an undefined 2-oxoglutarate dehydrogenase mutant of S. meliloti formed ineffective nodules (Duncan \& Fraenkel, 1979).

Since the Aap is regulated by the activity of the TCA cycle we tested the aapJ::Tn5-lacZ mutant strain RU543 for nodulation and acetylene reduction on peas. Of 25 nodule isolates from plants inoculated with strain RU543 all retained kanamycin resistance. Acetylene was reduced at a rate of $0.56 \pm 0.05 \mu \mathrm{mol} \mathrm{h}^{-1}$ per plant (mean \pm SEM, $n=3$ ) by strain RU543 compared to $0.45 \pm 0.02 \mu \mathrm{mol} \mathrm{h}^{-1}$ per plant (mean $\pm \mathrm{SEM}, n=3$ ) by strain 3841 , suggesting that loss of the Aap has no major effect on nitrogen fixation.

\section{DISCUSSION}

Mutation of the TCA cycle enzymes 2-oxoglutarate dehydrogenase and succinyl-CoA synthetase in $R$. leguminosarum strain 3841 leads to a severe reduction in amino acid uptake via the Aap. Uptake of other substrates such as glucose or succinate is also impaired in such mutants, probably as a result of general debilitation produced by the disruption of central metabolism, but the particularly marked reduction in amino acid transport suggests that there is a specific effect on this system.

Glutamate is excreted by sucDA mutants grown on both glucose $/ \mathrm{NH}_{4} \mathrm{Cl}$ and malate $/ \mathrm{NH}_{4} \mathrm{Cl}$. These results are consistent with several studies which indicate that a significant proportion of malate supplied to bacteroids under nitrogen-fixing conditions is converted to glutamate (Salminen \& Streeter, 1987; Kouchi et al., 1991; Miller et al., 1991; Salminen \& Streeter, 1992). Such studies have led to the suggestion that glutamate synthesis in the bacteroid is a consequence of inhibition of 2-oxoglutarate dehydrogenase by NADH (McDermott et al., 1989; Salminen \& Streeter, 1990). Although complete loss of 2-oxoglutarate dehydrogenase activity is artificial, the accumulation of glutamate by free-living sucDA mutants appears to support this hypothesis. Examination of the intracellular concentrations and excretion rates of 2-oxoglutarate and glutamate suggest that 2-oxoglutarate feeds into the glutamate pool. A further indication of the importance of transamination in determining the fate of metabolites, and hence regulating growth of $R$. leguminosarum, is provided by the finding that addition of aspartate to the growth medium leads to an increase in glutamate excretion by sucDA mutants. This is consistent with an increase in transamination of 2-oxoglutarate due to both the presence of an additional amino-donor in aspartate, and increased synthesis of 2-oxoglutarate from oxaloacetate released from aspartate. Although 2oxoglutarate is excreted by sucDA mutants, there is apparently no significant increase in the intracellular concentration of this metabolite in these mutants. This is consistent with a report that radioactivity failed to accumulate in 2-oxoglutarate in bacteroids supplied with labelled malate, an effect that was ascribed to rapid conversion of 2-oxoglutarate to glutamate (Salminen \& Streeter, 1990).

A reduction in 2-oxoglutarate dehydrogenase activity may be the reason for the escape from aspartate toxicity of strains RU116, RU137 and RU156. As already discussed, all of these strains have reduced 2oxoglutarate dehydrogenase activity which should lead to increased 2-oxoglutarate being available for deamination of aspartate. This may increase removal of aspartate through the transamination of 2-oxoglutarate to glutamate by aspartate aminotransferase.

Aspartate appears to be toxic at moderately high concentrations because it is actively accumulated by the $d c t$ system (Reid et al., 1996). Mutation of the $d c t$ system increases the concentration of aspartate required for toxicity from 50 to $150 \mathrm{mM}$ (Walshaw \& Poole, 1996). Aspartate at the moderate concentration of 10-20 mM in the growth medium has also been found to cause a severe reduction in amino acid uptake by the Aap in strain 3841 . This reduction, which is dependent on the presence of the Dct system, is not due to an inhibition of transcription (Reid et al., 1996; Walshaw \& Poole, 1996). The effect in TCA cycle mutants reported here is similar, the difference being that strains with mutations in either $s u c A$ or $s u c D$ no longer require aspartate to be present in the medium to cause the reduction in uptake. Given that the suc mutant strains RU116 and RU156 grown on glucose/ammonia have large increases in the concentration of intracellular glutamate, a plausible hypothesis to explain the reduction of uptake by the Aap is that it is caused by glutamate or one of its products. This is compatible with the reduction in uptake by the Aap in strain 3841 being dependent on the presence of aspartate in the growth medium, since this presumably leads to a high intracellular concentration of glutamate.

The Aap is an ABC transporter that we have proposed is either bi-directional or activates another channel/ transporter (Walshaw \& Poole, 1996). Cells of strain 3841 grown on glucose/aspartate excrete glutamate, but the aapJ mutant strain RU543 grown on glucose/ aspartate has glutamate excretion reduced by $76 \%$, demonstrating that the Aap is involved in this process (Walshaw \& Poole, 1996). It seems highly likely that the Aap is similarly required for glutamate excretion in suc mutants of $R$. leguminosarum. Excretion via the Aap occurs under conditions where uptake is very low, but transcription of the aap operon is not reduced. This suggests that the high intracellular concentration of glutamate, or a direct metabolic product of it, may mediate a post-translational modification of the Aap. Whatever the mechanism, the effect is to inhibit amino 
acid uptake under conditions where the intracellular level of glutamate is very high, leading to its excretion. High levels of transcription of the aap operon, under conditions where uptake is suppressed, is consistent with a role for the Aap in excretion.

While the Aap has a broad specificity for amino acid uptake, mutation of it allowed the kinetic identification of an amino acid uptake system with high affinity for alanine and its non-metabolizable analogue 2aminoisobutyrate (Walshaw \& Poole, 1996). Excretion of alanine but not glutamate has been detected for bacteroids from peas and soybeans (Appels \& Haaker, 1991; Kouchi et al., 1991; Rosendahl et al., 1992). The pyruvate dehydrogenase complex has strong structural and functional similarities to the 2-oxoglutarate dehydrogenase complex (Miles \& Guest, 1987; Guest \& Russell, 1992), and its inhibition by a low redox potential, as has been suggested for the 2-oxoglutarate dehydrogenase complex, might lead to the accumulation of pyruvate or its transamination product alanine. Labelling studies with pea bacteroids incubated in malate show a rapid rise in intracellular glutamate, followed by a smaller rise in alanine (Salminen \& Streeter, 1992). A key question is to what extent these amino acid pools are interconverted by transamination, versus their independent formation by pathways such as alanine and glutamate dehydrogenase.

The data in this paper suggest that amino acid excretion and PHB biosynthesis are two of the principal pathways that regulate carbon and the redox balance of the TCA cycle in $R$. leguminosarum. Both pathways act as a sink for carbon and reducing equivalents such as $\operatorname{NAD}(\mathrm{P}) \mathrm{H}$. While this has often been suggested, the work here shows they are clearly inter-regulated. These pathways become extremely important as sinks for excess $\mathrm{NAD}(\mathrm{P}) \mathrm{H}$, which happens when the TCA cycle is inhibited. This inhibition appears to occur in the bacteroid due to a low $\mathrm{O}_{2}$ tension and definitely occurs in TCA-cycle mutants. It seems likely that different strains and species of Rhizobium and Bradyrhizobium will partition carbon and reducing equivalents between these two and possibly other overflow pathways to varying extents, including bypass pathways such as the GABA shunt, which catabolizes glutamate, and the enzyme aspartase, which hydrolyses aspartate to fumarate and ammonia. Both of these pathways have been postulated to occur in R hizobium and at least some of the enzyme activities have been demonstrated (Poole et al., 1984; Jin et al., 1990; Kouchi et al., 1991; Fitzmaurice \& O’Gara, 1993).

A long-standing question concerning the excretion of amino acids by bacteroids of Rhizobium is the possible participation in shuttle mechanisms with the plant, such as the malate-aspartate shuttle (Kahn et al., 1985; McDermott et al., 1989; Appels \& Haaker, 1991). While the data in this paper do not exclude such mechanisms it is apparent that amino acid excretion occurs in $R$. leguminosarum as a normal response to limitation of the TCA cycle, independently of the plant macrosymbiont.
Furthermore, the demonstration that uptake systems such as the Aap influence efflux of amino acids, means that incubation of bacteroids or free-living cells in various amino and keto acids will lead to complex patterns of uptake and excretion. These patterns in themselves are not evidence that such cycles occur in $s i t u$. Excretion of a number of organic acids and amino acids has also been demonstrated in cells of $R$. etli subcultured several times in medium lacking thiamin and biotin (Cevallos et al., 1996). The activities of thiamindependent enzymes such as the 2-oxoglutarate dehydrogenase complex and pyruvate dehydrogenase complex were no longer detectable after sub-culture. These results are in agreement with the effect of mutating the 2oxoglutarate dehydrogenase complex.

The absence of any major effect on acetylene reduction in strain RU543, which is mutated in the Aap, suggests that glutamate is not an important carbon source in the bacteroid. This is supported by the absence of growth of this strain on glutamate as the carbon source in laboratory cultures (Walshaw \& Poole, 1996). Unless there is a nodule-specific transport system for glutamate in the bacteroid we would not expect strain RU543 to obtain glutamate from the plant in significant quantities. This suggests that glutamate cannot be an important carbon source provided by the plant to the bacteroid. Such a conclusion is consistent with data from soybean nodules where the peribacteroid membrane is impermeable to glutamate (Udvardi et al., 1990). The data presented here indicate that glutamate biosynthesis is important in overflow metabolism, not carbon nutrition, and supports the conclusions from labelling studies with pea and soybean bacteroids that glutamate is synthesized by bacteroids (Salminen \& Streeter, 1987, 1992).

\section{REFERENCES}

Appels, M. A. \& Haaker, H. (1991). Glutamate oxaloacetate transaminase in pea root nodules-participation in a malate/aspartate shuttle between plant and bacteroid Plant Physiol 95, 740-747.

Arwas, R., McKay, I. A., Rowney, F. R. P., Dilworth, M. J. \& Glenn, A. R. (1985). Properties of organic acid utilization mutants of Rhizobium leguminosarum strain 300. J Gen Microbiol 131, 2059-2066.

Bergersen, F. J. \& Turner, G. L. (1990). Bacteroids from soybean root nodules: accumulation of poly- $\beta$-hydroxybutyrate during supply of malate and succinate in relation to $\mathrm{N}_{2}$ fixation in flowchamber reactions. Proc R Soc Lond Ser B Biol Sci 240, 39-59.

Bergmeyer, H. U., Bernt, E., Mollering, H. \& Pfleiderer, G. (1974). L-Aspartate and L-asparagine. In Methods of Enzymatic Analysis, 2nd edn, pp. 1696-1700. Edited by H. U. Bergmeyer. New York: Academic Press.

Beringer, J.E. (1974). $\mathrm{R}$ factor transfer in Rhizobium leguminosarum. J Gen Microbiol 84, 188-198.

Bernt, E. \& Bergmeyer, H. U. (1974). L-Glutamate UV-assay with glutamate dehydrogenase and NAD. In Methods of Enzymatic Analysis, 2nd edn, pp. 1704-1708. Edited by H. U. Bergmeyer. New York: Academic Press.

Bolton, E., Higgisson, B., Harrington, A. \& O'Gara, F. (1986). Dicarboxylic acid transport in Rhizobium meliloti: isolation of 
mutants and cloning of dicarboxylic acid transport genes. Arch Microbiol 144, 142-146.

Buchanan-Wollaston, V. (1979). Generalized transduction in Rhizobium leguminosarum. J Gen Microbiol 112, 135-142.

Buck, D., Spencer, M. E. \& Guest, J. R. (1985). Primary structure of the succinyl-CoA synthetase of Escherichia coli. Biochemistry 24, $6245-6252$.

Cevallos, M. A., Encarnacion, S., Leija, A., Mora, Y. \& Mora, J. (1996). Genetic and physiological characterization of a Rhizobium etli mutant strain unable to synthesize poly-betahydroxybutyrate. J Bacteriol 178, 1646-1654.

Darlison, M. G., Spencer, M. E. \& Guest, J. R. (1984). Nucleotidesequence of the sucA gene encoding the 2-oxoglutarate dehydrogenase of Escherichia coli K12. Eur J Biochem 141, 351-359.

Day, D. A. \& Udvardi, M. K. (1993). Metabolite exchange across symbiosome membranes. Symbiosis 14, 175-189.

Dilworth, M. J., Arwas, R., McKay, I. A., Saroso, S. \& Glenn, A. R. (1986). Pentose metabolism in Rhizobium leguminosarum MNF300 and in cowpea Rhizobium NGR234. J Gen Microbiol 132, 2733-2742.

Duncan, M. J. \& Fraenkel, D. G. (1979). $\alpha$-Ketoglutarate dehydrogenase mutant of Rhizobium meliloti. J Bacteriol 37, 415-419.

Encarnacion, S., Dunn, M., Willms, K. \& Mora, J. (1995). Fermentative and aerobic metabolism in Rhizobium etli. J Bacteriol 177, 3058-3066.

Engelke, T., Jagadish, M. N. \& Puhler, A. (1987). Biochemical and genetical analysis of Rhizobium meliloti mutants defective in $\mathrm{C}_{4}$ dicarboxylate transport. J Gen Microbiol 133, 3019-3029.

Finan, T. M., Wood, J. M. \& Jordan, D. C. (1983). Symbiotic properties of $\mathrm{C}_{4}$-dicarboxylic acid transport mutants of Rhizobium leguminosarum. J Bacteriol 154, 1403-1413.

Finan, T. M., McWhinnie, E., Driscoll, B. \& Watson, R. J. (1991). Complex symbiotic phenotypes result from gluconeogenic mutations in Rhizobium meliloti. Mol Plant-Microbe Interact 4, 386-392.

Fitzmaurice, A. M. \& O'Gara, F. (1993). A Rbizobium meliloti mutant, lacking a functional gamma-aminobutyrate (GABA) bypass, is defective in glutamate catabolism and symbiotic nitrogen fixation. FEMS Microbiol Lett 109, 195-202.

Glenn, A. R. \& Dilworth, M. J. (1981). Oxidation of substrates by isolated bacteroids and free-living cells of Rhizobium leguminosarum 3841. J Gen Microbiol 126, 243-247.

Glenn, A. R., Poole, P. S. \& Hudman, J. F. (1980). Succinate uptake by free-living and bacteroid forms of Rhizobium leguminosarum. J Gen Microbiol 119, 267-271.

Glenn, A. R., McKay, I. A., Arwas, R. \& Dilworth, M. J. (1984). Sugar metabolism and the symbiotic properties of carbohydrate mutants of Rhizobium leguminosarum. J Gen Microbiol 130, 239-245.

Glenn, A. R., McKay, I. A., Arwas, R. \& Dilworth, M. J. (1984). Sugar metabolism and the symbiotic properties of carbohydrate mutants of Rhizcbium leguminosarum. J Gen Microbiol 130, 239-245.

Guest, J. R. (1992). Oxygen-regulated gene expression in Escherichia coli. J Gen Microbiol 138, 2253-2263.

Guest, J. R. \& Russell, G. C. (1992). Complexes and complexities of the citric acid cycle in Escherichia coli. Curr Top Cell Regul 33, 231-247.

Hirsch, P. R. \& Beringer, J. E. (1984). A physical map of pPH1JI and pJB4JI. Plasmid 12, 139-141.

Jin, H. N., Dilworth, M. J. \& Glenn, A. R. (1990). 4-Aminobutyrate is not available to bacteroids of cowpea Rhizobium MNF2030 in snake bean nodules. Arch Microbiol 153, 455-462.

Johnston, A. W. B. \& Beringer, J. E. (1975). Identification of the Rhizobium strains in pea root nodules using genetic markers. $J$ Gen Microbiol 87, 343-350.

Kahn, M. L., Kraus, J. \& Sommerville, J. E. (1985). A model of nutrient exchange in the Rhizobium-legume symbiosis. In Nitrogen Fixation Research Progress, pp. 193-199. Edited by H. J. Evans, P. J. Bottomley \& W. E. Newton. Dordrecht: Martinus Nijhoff.

Kouchi, H., Fukai, K. \& Kihara, A. (1991). Metabolism of glutamate and aspartate in bacteroids isolated from soybean root nodules. $J$ Gen Microbiol 137, 2901-2910.

Kramer, R. (1994). Secretion of amino acids by bacteria-physiology and mechanism. FEMS Microbiol Rev 13, 75-93.

Law, J. H. \& Slepecky, R. A. (1961). Assay of poly- $\beta$ hydroxybutyric acid. J Bacteriol 82, 33-42.

McDermott, T. R., Griffith, S. M., Vance, C. P. \& Graham, P. H. (1989). Carbon metabolism in Bradyrhizobium japonicum bacteroids. FEMS Microbiol Lett 63, 327-340.

McKay, I. A., Glenn, A. R. \& Dilworth, M. J. (1985). Gluconeogenesis in Rhizobium leguminosarum MNF3841. J Gen Microbiol 131, 2067-2073.

Meissner, P. S., Sisk, W. P. \& Berman, M. L. (1987). Bacteriophage cloning system for the construction of directional cDNA libraries. Proc Natl Acad Sci USA 84, 4171-4175.

Miles, J. S. \& Guest, J. R. (1987). Molecular genetic aspects of the citric acid cycle of Escherichia coli. Biochem Soc Symp 54, 45-65. Miller, J. H. (1972). Experiments in Molecular Genetics. Cold Spring Harbor, NY: Cold Spring Harbor Laboratory.

Miller, R. W., McRae, D. G. \& Jot, K. (1991). Glutamate and gamma-aminobutyrate metabolism in isolated Rhizobium meliloti bacteroids. Mol Plant-Microbe Interact 4, 37-45.

Nicholls, D. J., Sundaram, T. K., Atkinson, T. \& Minton, N. P. (1990). Cloning and nucleotide sequences of the $m d h$ and $s u c D$ genes from Thermus aquaticus B. FEMS Microbiol Lett 70, 7-14.

Nishiyama, M., Horinouchi, S. \& Beppu, T. (1991). Characterization of an operon encoding succinyl-CoA synthetase and malate dehydrogenase from Thermus flavus AT-62 and its expression in Escherichia coli. Mol Gen Genet 226, 1-9.

Osteras, M., Finan, T. M. \& Stanley, J. (1991). Site-directed mutagenesis and DNA sequence of pckA of Rhizobium NGR234, encoding phosphoenolpyruvate carboxykinase-gluconeogenesis and host-dependent symbiotic phenotype. Mol Gen Genet 230, 257-269.

Patriarca, E. J., Chiurazzi, M., Manco, G., Riccio, A., Lamberti, A., Depaolis, A., Rossi, M., Defez, R. \& laccarino, M. (1992). Activation of the Rbizobium leguminosarum glnIl gene by NtrC is dependent on upstream DNA sequences. Mol Gen Genet 234, 337-345.

Poole, P. S., Dilworth, M. J. \& Glenn, A. R. (1984). Acquisition of aspartase activity in Rhizobium leguminosarum WU235. J Gen Microbiol 130, 881-886.

Poole, P. S., Franklin, M., Glenn, A. R. \& Dilworth, M. J. (1985). The transport of L-glutamate by Rhizobium leguminosarum involves a common amino acid carrier. J Gen Microbiol 131, 1441-1448.

Poole, P. S., Blyth, A., Reid, C. J. \& Walters, K. (1994a). myoInositol catabolism and catabolite regulation in Rhizobium leguminosarum bv. viciae. Microbiology 140, 2787-2795.

Poole, P. S., Schofield, N. A., Reid, C. J., Drew, E. M. \& Walshaw, 
D. L. (1994b). Identification of chromosomal genes located downstream of $d c t D$ that affect the requirement for calcium and the lipopolysaccharide layer of Rhizobium leguminosarum. Microbiology 140, 2797-2809.

Povolo, S., Tombolini, R., Morea, A., Anderson, A. J., Casella, S. \& Nuti, M. P. (1994). Isolation and characterization of mutants of Rhizobium meliloti unable to synthesize poly-betahydroxybutyrate. Can J Microbiol 40, 823-829.

Quandt, J. \& Hynes, M. F. (1993). Versatile suicide vectors which allow direct selection for gene replacement in Gram-negative bacteria. Gene 127, 15-21.

Reeves, H. C., Rabin, R., Wegener, W. S. \& Ajl, S. J. (1971). Assays of enzymes of the tricarboxylic acid and glyoxylate cycles. Methods Micro 6A, 425-462.

Reid, C. J., Walshaw, D. L. \& Poole, P. S. (1996). Aspartate transport by the Dct system in Rhizobium leguminosarum negatively affects nitrogen-regulated operons. Microbiology 142, 2603-2612.

Ronson, C. W. \& Primrose, S. B. (1979). Carbohydrate metabolism in Rhizobium trifolii: identification and symbiotic properties of mutants. J Gen Microbiol 112, 77-88.

Ronson, C. W., Lyttleton, P. \& Robertson, J. G. (1981). $C_{4}-$ Dicarboxylate transport mutants of Rhizobium trifolii form ineffective nodules on Trifolium repens. Proc Natl Acad Sci USA 78, 4284-4288.

Rosendahl, L., Dilworth, M. J. \& Glenn, A. R. (1992). Exchange of metabolites across the peribacteroid membrane in pea root nodules. J Plant Physiol 139, 635-638.

Ruvkun, G. B. \& Ausubel, F. M. (1981). A general method for sitedirected mutagenesis in prokaryotes. Nature 289, 85-88.

Salminen, S. O. \& Streeter, J. G. (1987). Involvement of glutamate in the respiratory metabolism of Bradyrbizobium japonicum bacteroids. J Bacteriol 169, 495-499.

Salminen, S. O. \& Streeter, J. G. (1990). Factors contributing to the accumulation of glutamate in Bradyrhizobium japonicum bacteroids under microaerobic conditions. J Gen Microbiol 136, 2119-2126.

Salminen, S. O. \& Streeter, J. G. (1992). Labeling of carbon pools in Bradyrhizobium japonicum and Rhizobium leguminosarum bv. viciae bacteroids following incubation of intact nodules with ${ }^{14} \mathrm{CO}_{2}$. Plant Physiol 100, 597-604.

Sambrook, J., Fritsch, E. F. \& Maniatis, T. (1989). Molecular
Cloning: a Laboratory Manual, 2nd edn. Cold Spring Harbor, NY : Cold Spring Harbor Laboratory.

Saroso, S., Dilworth, M. J. \& Glenn, A. R. (1986). The use of activities of carbon catabolic enzymes as a probe for the carbon nutrition of snakebean nodule bacteroids. J Gen Microbiol 132, 243-249.

Simon, R., Priefer, U. \& Puhler, A. (1983). A broad host-range mobilization system for in vivo genetic engineering: transposon mutagenesis of Gram-negative bacteria. Biotechnology 1, 784-791.

Simon, R., Quandt, J. \& Klipp, W. (1989). New derivatives of transposon Tn5 suitable for mobilization of replicons, generation of operon fusions and induction of genes in Gram-negative bacteria. Gene 80, 161-169.

Spaink, H.P., Okker, R. J. H., Wijffelman, C. A., Pees, E. \& Lugtenberg, B. J. J. (1987). Promoters in the nodulation region of the Rbizobium leguminosarum SYM plasmid PRL1JI. Plant Mol Biol 9, 27-39.

Spencer, M. E., Darlison, M. G., Stephens, P. E., Duckenfield, I. K. \& Guest, J.R. (1984). Nucleotide-sequence of the $s u c B$ gene encoding the dihydrolipoamide succinyltransferase of Escherichia coli $\mathrm{K} 12$ and homology with the corresponding acetyltransferase. Eur J Biochem 141, 361-374.

Streeter, J. G. (1987). Carbohydrate, organic acid, and amino acid composition of bacteroids and cytosol from soybean nodules. Plant Physiol 85, 768-773.

Tempest, D. W. \& Neijssel, O. M. (1992). Physiological and energetic aspects of bacterial metabolite overproduction. FEMS Microbiol Lett 100, 169-176.

Udvardi, M. K., Ou Yang, L.-J., Young, S. \& Day, D. A. (1990). Sugar and amino acid transport across symbiotic membranes from soybean nodules. Mol Plant-Microbe Interact 3, 334-340.

Walshaw, D. L. \& Poole, P. S. (1996). The general L-amino acid permease of Rhizobium leguminosarum is an $\mathrm{ABC}$ uptake system that influences efflux of solutes. Mol Microbiol 21, 1239-1252.

Wood, W. B. (1966). Host specificity of DNA produced by Escherichia coli; bacterial mutations affecting the restriction and modification of DNA. J Mol Biol 16, 118-133.

Received 14 October 1996; revised 10 February 1997; accepted 19 February 1997. 